\title{
Cr(III) adsorption by cluster formation on boehmite nanoplates in
}

\section{highly alkaline solution}

Wenwen Cui ${ }^{1,2,3}$, Xin Zhang ${ }^{1, *}$, Carolyn I. Pearce ${ }^{4}$, Ying Chen ${ }^{1}$, Shuai Zhang ${ }^{1,5}$, Wen Liu $^{6}$, Mark H. Engelhard ${ }^{6}$, Libor Kovarik ${ }^{6}$, Meirong Zong ${ }^{1,7}$, Hailin Zhang ${ }^{1,2,3}$, Eric D. Walter $^{6}$, Zihua Zhu ${ }^{6}$, Steve M. Heald ${ }^{8}$, Micah P. Prange ${ }^{1}$, James J. De Yoreo ${ }^{1,5}$, Shili Zheng $^{2}$, Yi Zhang ${ }^{2}$, Sue B. Clark ${ }^{1,9}$, Ping Li ${ }^{2, *}$, Zheming Wang ${ }^{1, *}$, and Kevin M. Rosso ${ }^{1, *}$ 1 - Physical \& Computational Science Directorate, Pacific Northwest National Laboratory, Richland, Washington 99354, USA

2 -National Engineering Laboratory for Hydrometallurgical Cleaner Production Technology, Key Laboratory of Green Process and Engineering, Institute of Process Engineering, Chinese Academy of Sciences, Beijing, 100190, China

3 - University of Chinese Academy of Sciences, Beijing, 100049, China

4 - Energy \& Environment Directorate, Pacific Northwest National Laboratory, Richland, WA, USA

5 - Department of Materials Science and Engineering, University of Washington, Seattle, Washington 98195, USA

6 - Environmental Molecular Sciences Laboratory, Pacific Northwest National Laboratory, Richland, Washington 99354, USA

7 - School of Earth Sciences and Engineering, Nanjing University, Nanjing, Jiangsu Province, 210023.

8 - Advanced Photon Source, Argonne National Laboratory, Lemont, IL 60439, USA

9 - Department of Chemistry, Washington State University, Pullman, WA, USA

Number of pages: 6 including title page

Number of figures: 4 


\section{Calculation of adsorption site density on boehmite nanoplate surface}

The intensity of Al sites on (010) and (101) faces of boehmite crystals is $9.43 / \mathrm{nm}^{2}$ and $5.24 / \mathrm{nm}^{2}$, respectively. The BET surface area of as synthesized boehmite nanoplates is $55.22 \mathrm{~m}^{2} / \mathrm{g}$. The surface area ratio of $(010)$ to $(101)$ is $3.26: 1$ based on measured size. Thus the exposed Al sites in the material is $4.67 \times 10^{20} / \mathrm{g}$, which is $0.778 \mathrm{mM} \mathrm{Al}$ on $1 \mathrm{~g}$ boehmite surface. The maximum adsorption capacity of boehmite should be $0.778 \mathrm{mM}$ $\mathrm{Cr}(\mathrm{III}) / \mathrm{g} \mathrm{AlOOH}$ nanoplates, which is $40.46 \mathrm{mg} \mathrm{Cr}(\mathrm{III}) / \mathrm{g}$ AlOOH nanoplates. The maximum adsorption capacity of boehmite (010) surface is $0.663 \mathrm{mM}(34.48 \mathrm{mg})$ $\mathrm{Cr}(\mathrm{III}) / \mathrm{g} \mathrm{AlOOH}$ nanoplates. Currently, the adsorption concentration of $\mathrm{Cr}(\mathrm{III})$ is 19.85 $\mathrm{mg} \mathrm{Cr}(\mathrm{III}) / \mathrm{g}$ AlOOH nanoplates, which is around 50\% coverage for the total surface area $[(010)$ plus $(101)]$ for the monolayer adsorption. 


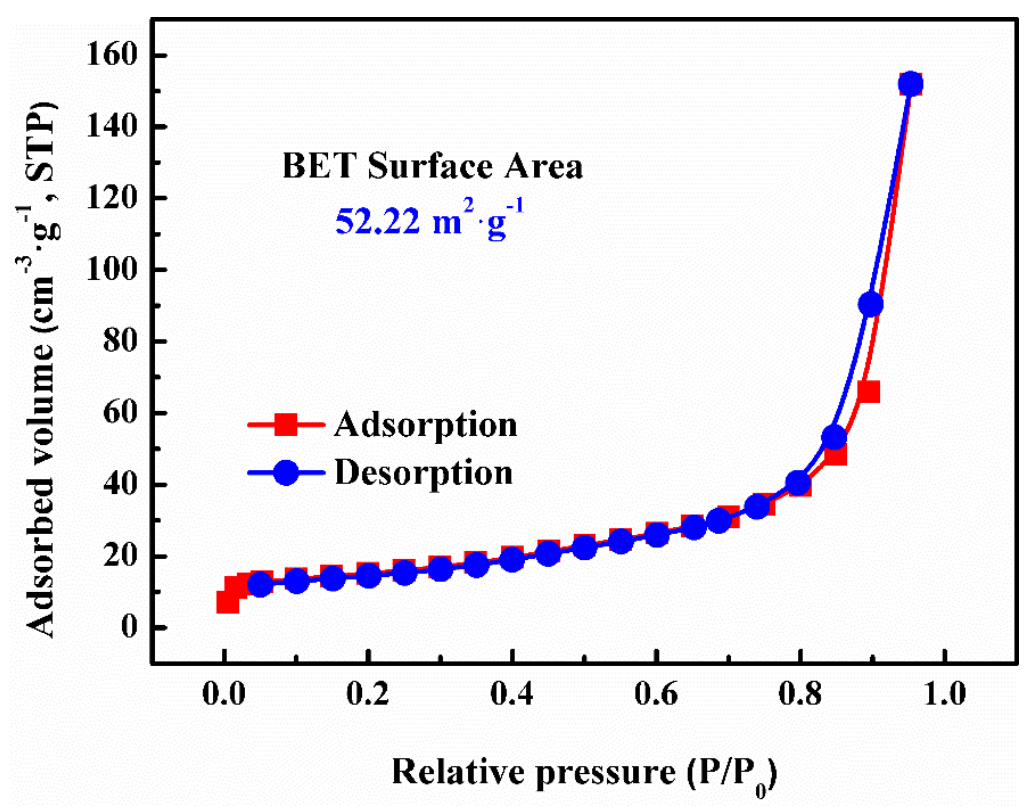

Figure S1. Nitrogen adsorption-desorption isotherms curves of as-prepared boehmite 


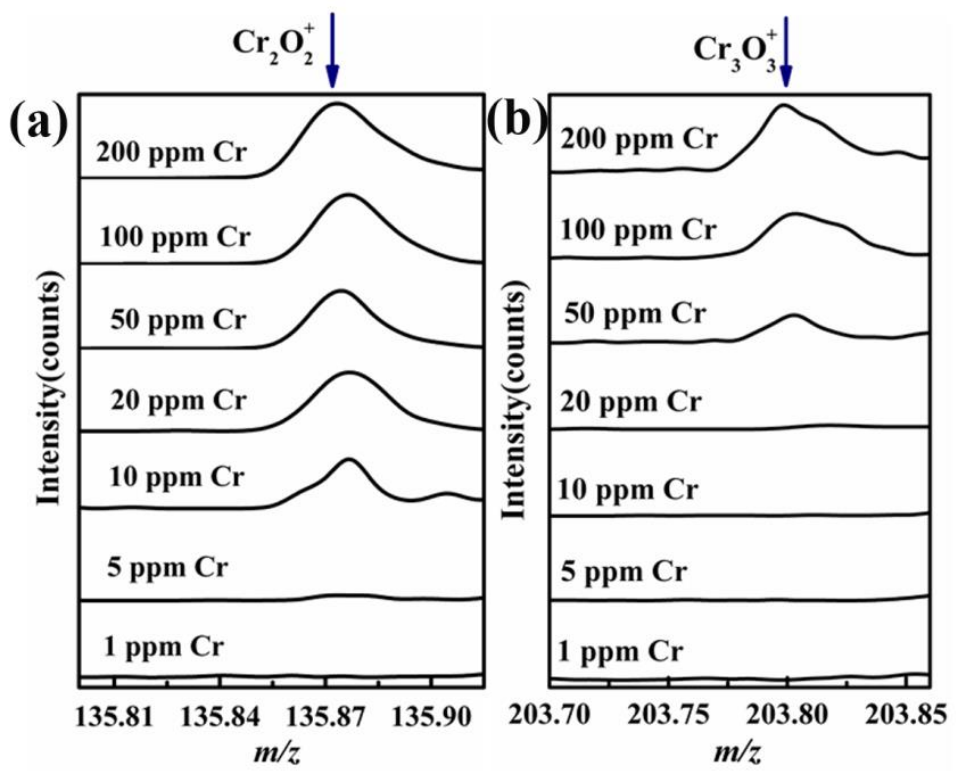

Figure S2. Regional spectra for the $\mathrm{Cr}_{2} \mathrm{O}_{2}{ }^{+}$and $\mathrm{Cr}_{3} \mathrm{O}_{3}{ }^{+}$secondary ions (a, b) of $\mathrm{Cr}(\mathrm{III})$ adsorbed boehmite at different initial concentration of $\mathrm{Cr}$ (III) 
(A)

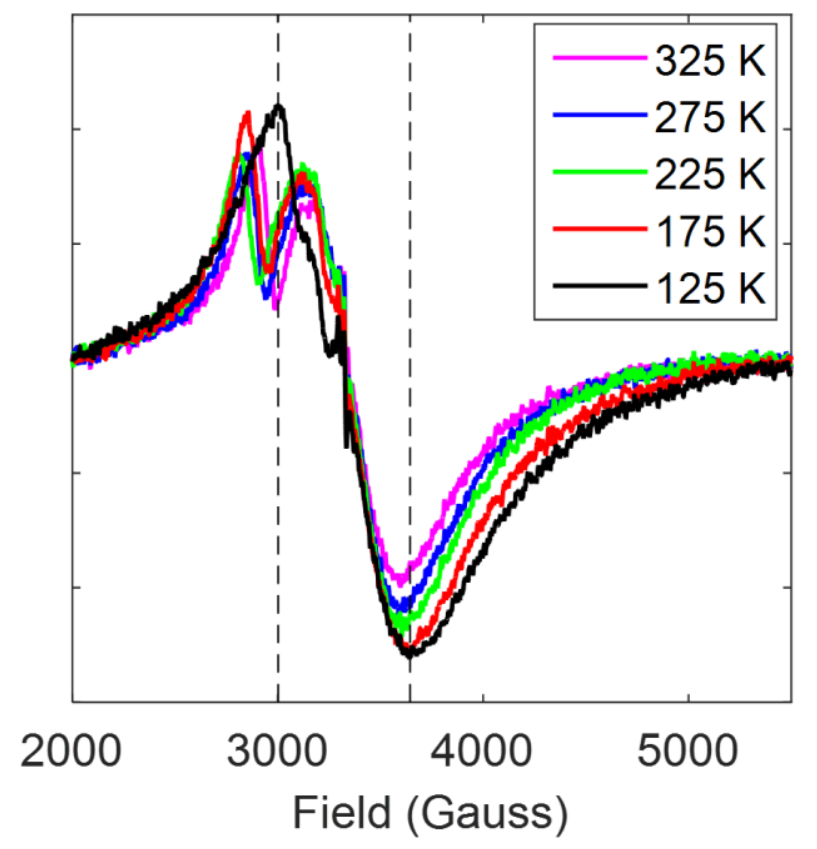

(B)

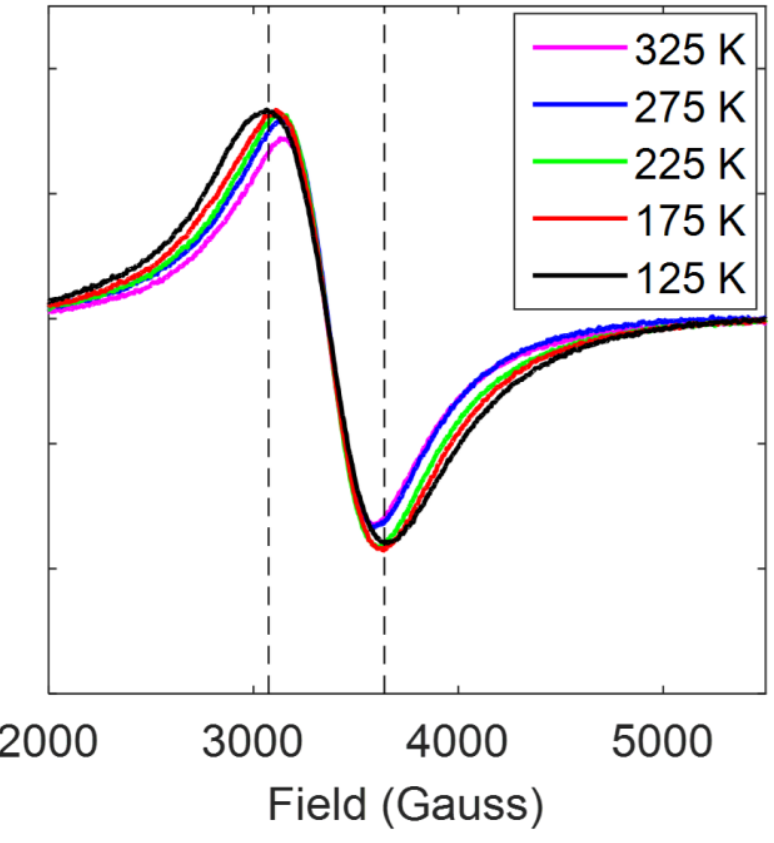

Figure S3. EPR spectra of Cr-B-1 ppm (A) and Cr-B-100 ppm (B) collected at temperatures ranging from $125 \mathrm{~K}$ to $325 \mathrm{~K}$. 


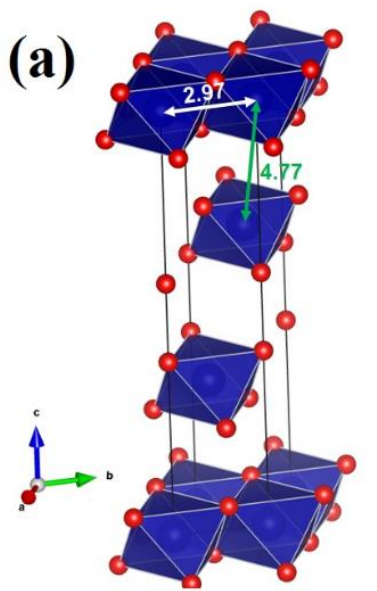

(b)

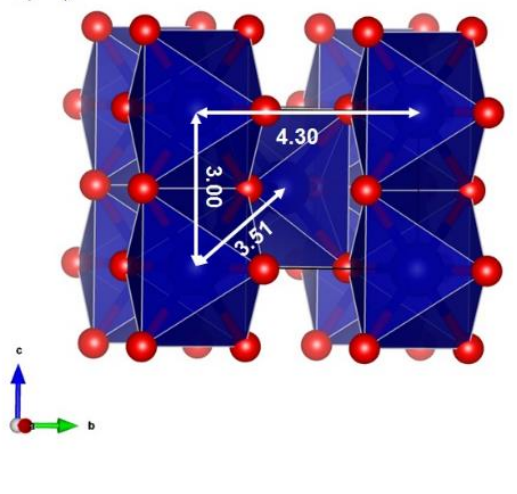

(c)

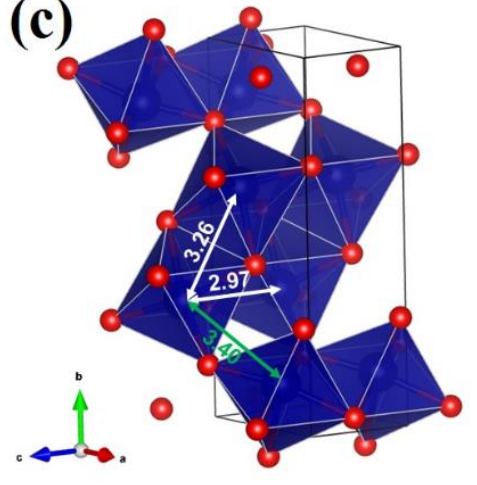

Figure S4. Crystal structure of Grimaldiite $(\alpha-\mathrm{CrOOH})(\mathrm{a})$, Guyanaite $(\beta-\mathrm{CrOOH})(b)$, and Bracewellite $(\gamma-\mathrm{CrOOH})(\mathrm{c})$. 